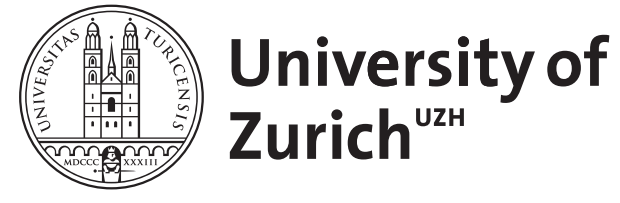

\author{
Sense of coherence in adolescents \\ Buddeberg-Fischer, Barbara ; Klaghofer, Richard ; Schnyder, Ulrich
}

\begin{abstract}
Summary: Objectives: The course of sense of coherence (SOC) in adolescents over an 18month-period and the correlation between individual variability in the SOC scale scores and physical and psychological symptoms were examined. Methods: A sample of 341 students from two Swiss senior high schools were investigated by means of questionnaires three times over a period of 18 months. The questionnaire comprised the SOC scale (SOC-13) and measures of physical and psychological impairment. Results: Male adolescents had a significantly higher SOC mean score than females. Significant negative correlations between the SOC and the symptom scales were found in both genders. Higher symptom scores correlated with a greater variability of the SOC scores. Independent of their sex, individuals with a high SOC score at $t$, showed less variability in the SOC values over time than individuals with low SOC scores. In adolescents who revealed low symptom scores the SOC scale scores almost reached levels seen in adults and remained relatively stable over time. Conclusions: The results suggest a certain degree of stability of SOC in middle to late adolescence
\end{abstract}

DOI: https://doi.org/10.1007/bf01321667

Posted at the Zurich Open Repository and Archive, University of Zurich ZORA URL: https://doi.org/10.5167/uzh-156322

Journal Article

Published Version

Originally published at:

Buddeberg-Fischer, Barbara; Klaghofer, Richard; Schnyder, Ulrich (2001). Sense of coherence in adolescents. Sozial- und Präventivmedizin, 46(6):404-410.

DOI: https://doi.org/10.1007/bf01321667 
1 Department of Psychosocial Medicine, University Hospital Zurich

2 Psychiatric Outpatient Clinic, University Hospital Zurich

\section{Sense of coherence in adolescents}

Summary

Objectives: The course of sense of coherence $(50 \mathrm{C})$ in adolescants over an 18 month-period and the correlation between individual variability in the $50 \mathrm{C}$ scale scores and physical and psychological symptoms were examined.

Methods: A sample of 341 students from two Swiss senio. high schook wre investigated by meand of questionnaires three times over a period of 18 months. The questionnaive comprised the $50 \mathrm{C}$ scale (SOck-13) and measures of physical and psychological impairment.

Results: Male adolescents had significanty higher soc mean score than females. Significant negative correlations between the SoC and the symptom scales were found in both genders. Higher symptom scores correlated with a greater variability of the $50 C$ scores. Indeperdent of their sex, individuals with a high SOC score at ? showed less variability in the soc values over time than individuats with low SOC scores. In adolescents who revealed low symptom scores the soc scale scores almost reached levels seen in aduhs and remained relatively stable over time.

Conclusions: The results suggest a certain degree of stability of soc in middle to late adolescence.

Key-Words: Sense of coherence - Physical and psychological symptoms - Adolescents.

The sense of coherence scale (SOC) was developed by Antonovsky as a scientific measure related to the concept of salutogenesis". He defined coherence as a "global orientation that expresses the extent to which one has a pervasive, though dynamic feeling of confidence, that 1) the stimuli deriving from one's internal and external environments in the course of living are structured, predictable, and explicable; 2) the resources are available to one to meet the demands posed by these stimuli; and 3) these demands are challenges, worthy of investment and engagement"1. The SOC scale is a self-rating questionnaire that measures the extent to which an individual is likely to construe a stressor as comprehensible and worth overcoming, and the individual's appraisal that he or she will manage to overcome such stressors $^{1}$. The SOC instrument is essentially a measure of an individual's resistance in the face of stress ${ }^{2}$. Individuals with high SOC scores are those likely to perceive stressors as predictable and explicable, have confidence in their capacity to overcome stressors, and judge it worthwhile to rise to the challenge they face. Low SOC scores indicate the relative absence of these beliefs. The concept has similarities with other theories of self-efficacy ${ }^{3}$, hardiness ${ }^{4}$, resilien$\mathrm{ce}^{5}$, and dispositional optimism ${ }^{6}$. As with other personality characteristics, the individual's beliefs, world view, and capacity to overcome the challenges of life develops from childhood to adolescence to adulthood.

Since its introduction by Antonovsky in 1983 the SOC scale has been widely used in different fields of research as a measure of an individual's resilience in the face of stress. It has been applied in patients as well as general populationbased samples ${ }^{2}$. SOC values are usually described as mean total scores ranging from 1 to 7 ; a value of 1 refers to the minimum, 7 represents the maximum value, indicating a high sense of coherence. SOC mean scores in the general adult population have been reported to be 5.2-5.3 in Sweden ${ }^{7,8}$, and 4.7 in an Israeli Jewish national sample ${ }^{2}$. In an epidemiological survey recently carried out in Germany with a community-based representative sample of $\mathrm{N}=2067^{\circ}$, the SOC mean score was 4.86 (women: 4.81 ; men: 4.92 ).

Only few studies have investigated stability of the sense of coherence over time ${ }^{10-12}$. Antonovsky claimed that sense 
of coherence develops in childhood and adolescence and remains stable during adulthood ${ }^{1}$. However, a number of studies have found significantly positive correlations between SOC scale scores and age in adult samples ${ }^{13,14}$. Epidemiological data regarding possible gender differences in the SOC scores are inconsistent; there appears to be a tendency towards male subjects showing higher SOC mean scale scores than females ${ }^{2,9}$.

In adult patient samples, it has been reported that SOC can predict short-term or long-term outcome of psychiatric and somatic health problems ${ }^{7,15-18}$. In rehabilitation medicine SOC may also be understood as a mediator between activities (disabilities) and participation (handicap) ${ }^{14}$. SOC correlates negatively $(r=0.3$ to 0.8$)$ with physical complaints and with psychological disturbances, particularly with anxiety and depressive symptoms ${ }^{19}$. As a consequence, several authors have claimed that $\mathrm{SOC}$ may be primarily a reflection of psychiatric (mainly affective) morbidity ${ }^{16,17}$.

While a considerable body of knowledge about sense of coherence has been accumulated in the literature over the last 15 years in adult samples, only very few studies have been published that addressed SOC in childhood and adolescence. Antonovsky and Sagy reported that boys had higher SOC mean scale scores than girls ${ }^{20}$. However, in another Istaeli sample of adolescents, the SOC mean score was 4.54 for girls, and 4.51 for boys ${ }^{21}$. In a subsample of 74 adolescents aged 16 to 19 from the German epidemiological survey mentioned above, the SOC mean score was 4.74 (females: 4.59, males: 4.90 ) and showed significantly negative correlations with measures of psychopathology and physical complaints 9 .

The aim of this study was to investigate 1) the mean SOC scale scores in male and female adolescents, 2 ) the course of SOC scale scores over an 18-month-period and its testretest-reliability in adolescent females and males, 3) correlations between the SOC questionnaire and measures of psychopathology, and 4) correlations between individual variability in the SOC scale scores over time and by sex and psychopathology in adolescents.

\section{Methods}

\section{Sample and procedure}

Schools today are requested to provide health promotion activities as part of their curriculum. Teachers and students of two senior high schools in the Canton of Zurich, Switzerland developed materials and lessons for a health promotion programme, which were integrated into the official school curriculum over a period of 12 months $^{22}$. As part of the longitudinal study students rated their sense of coherence as well as their physical and psychological wellbeing.

Both of the participating schools were public senior high schools preparing for entering university. Apart from the official curriculum providing languages (ancient and modern) and sciences they have another focus on music and arts. The student body of both schools is predominantly female. After giving informed consent all students attending grades 9 to 11 were examined three times by means of questionnaire: $t_{1}$ (baseline), $t_{2}\left(12\right.$ months after $\left.t_{1}\right)$ and $t_{3}\left(18\right.$ months after $t_{1}$. Between $t_{1}$ and $t_{2}$ the health promotion lessons were implemented as part of the official school curriculum. 565 students met inclusion criteria for the study. 370 students were assessed at all three measurement points while 195 (34.5\%) dropped out during the observation period. Dropout rates were evenly distributed among the school classes and corresponded with school attendance records. Students who dropped out were significantly older than those remaining in the study sample $(\mathrm{p}<0.01)$. They also scored significantly lower on the SOC scale and showed significantly higher scores on the physical and psychological symptom scales $(p<0.05)$. The age range of the total student body was 15 to 21 years. There were only few students aged $15(n=8$ females, 1 male) or $\geq 20$ ( $n=7$ females, 6 males). Because they are not representative of the student population under investigation, these two age cohorts $(15$ and $\geq 20$ years) were excluded from analyses. Seven students with assessments at all three measurement points had to be excluded from the analyses because of missing data in the individual questionnaires. Thus $\mathrm{n}=341$ students remained for data analyses: 254 females $(74.5 \%)$ and 87 males $(25.5 \%)$.

The mean age of the 341 students was 17.4 years ( $\mathrm{SD}=0.98$ years, age range $16-19$ years) at $t_{1} .85 \%$ lived with both parents, $14.4 \%$ with one parent and $0.6 \%$ in other settings. Social status, based on the father's professional position, was classified into four categories ${ }^{23}$. In our sample, $6.2 \%$ of the students belonged to the lower social status (unskilled and partly unskilled occupations), $11.7 \%$ to the lower middle social status (skilled occupations), $32.0 \%$ to the intermediate middle social status (intermediate occupations) and $50.1 \%$ to the upper middle social status (professionals and self-employed). There was no statistical difference in SOC scores between the four social status categories. Most students (59.5\%) lived in villages and small towns, $40.5 \%$ were residents of larger cities or metropolitan areas. The vast majority ( $94.4 \%$ ) were Swiss, $1.8 \%$ were of German or Austrian origin and 3.8\% were of non-Germanspeaking origin. 


\section{Instruments}

The complete version of the SOC Questionnaire ${ }^{2}$ consists of 29 items. In the present study the short version (13 items) was used, which has been reported to have psychometric properties comparable to the original version ${ }^{2,9}$. Items are rated on a seven-point Likert scale. The endpoints of the scale are labelled with the extreme answers (a value of 1 refers to the minimum, 7 represents the maximum value, indicating a high sense of coherence). For instance, subjects are asked "Until now your life has had: no clear goals or purpose at all (answer 1) ... very clear goals and purpose (answer 7)"; "Do you have the feeling that you are in an unfamiliar situation and don't know what to do? very often (answer 1) ... very seldom or never (answer 7)". Test properties such as shortterm test-retest reliability in adults (0.52-0.97) and internal consistency of the SOC questionnaire are excellent ${ }^{2,9,24}$. In a German representative survey a mean value of 5.01 (SD = 0.89 ) was found for the short version of the SOC scale (13 items); the internal consistency (Cronbach's Alpha) was 0.85 and the split-half reliability (Spearman-Brown) was 0.80 ; the short version correlated with the long version ( 29 items) at $0.94^{9}$. In previous studies, factor analyses have failed to reproduce the three subscales (comprehensibility, manageability, meaningfulness) proposed by Antonovsky ${ }^{2}$. It has therefore been recommended that only the total SOC scale score be used in research $2,9,24$. The SOC-13 instrument (short version) has no subscales; consequently only the SOC total scale score (adding up the values of the 13 items divided by the number of items) was used in the present study. The Giessener Beschwerdebogen GBB-24 (Giessen Physical Complaint List ${ }^{25}$ ) is a short version of the GBB and was administered to assess the physical state of health. The overall distress score (total score) was used for analyses. Psychological impairment was assessed by means of the SelfReport Symptom Check List (SCL-90-R, scales 2 $-6^{26}$ ). For analyses the General Symptom Index (GSI-48) was used. The Allgemeine Depressionsskala ADS-K ${ }^{27}$ examines predominantly depressive mood and consists of 15 items.

\section{Statistical procedures}

Analysis of variance with repeated measurements was performed to investigate the course of the SOC scale scores and symptom scales over time; independent variables being time and sex, dependent variables being the SOC questionnaire and the symptom scales GBB, SCL and ADS. Pearson's correlation coefficient was used to examine the test-retest reliability of the SOC scale and the correlation between the SOC scale and symptom scales. The coefficient of variation (CFVAR) was used to describe intraindividual variability in the SOC measurement over time.

\section{Results}

Table 1 shows the course of the SOC scale mean scores over time in the adolescent sample. The mean scores of females and males reached almost the same level during the time period $t_{1}$ to $t_{2}$ and increased significantly from $t_{2}$ to $t_{3}$. Although we found statistically significant results $\left(t_{2}\right.$ to $\left.t_{3}\right)$, the absolute differences between mean scores were small. Males had a significantly higher SOC mean score than females. There was no significant interaction between sex and time. The internal consistency (Cronbach's Alpha) was 0.82 at $t_{1}$ and $t_{2}$, and 0.87 at $t_{3}$. The test-retest reliability of the SOC questionnaire (Table 2) was high. As expected, the reliability was lower $(r=0.69)$ between $t_{1}$ and $t_{2}$ (12month interval) than between $t_{2}$ and $t_{3}(r=0.77$, six-month interval).

Correlations between the SOC scale scores and the symptom scales: There were significantly negative correlations between the SOC scale scores and the three symptom scales: GBB: -0.54 , SCL: -0.61 and ADS; -0.56 ( $p<0.001)$. The correlation was independent of the participants' sex.

Individual variability of the SOC scale scores: The coefficient of variation (CFVAR) of the SOC scale score had an average of 0.09 ( $\mathrm{SD}=0.06$, range 0.00 to 0.31 ) and was not

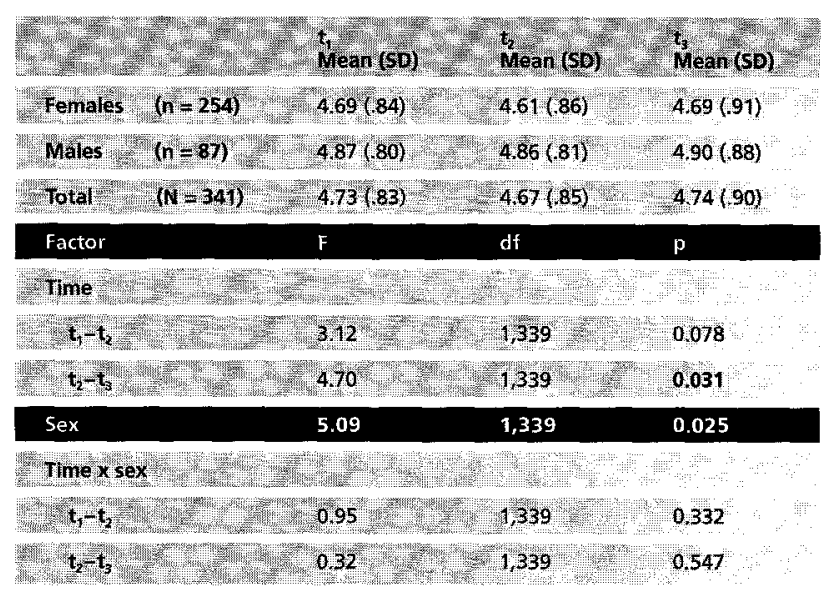

Table 1 Mean scores, standard deviations und results of analysis of variance of the sense of coherence questionnaire over time ( $t_{3}=$ initial assessment, $t_{2}=+12$ months, $t_{3}=+18$ months)

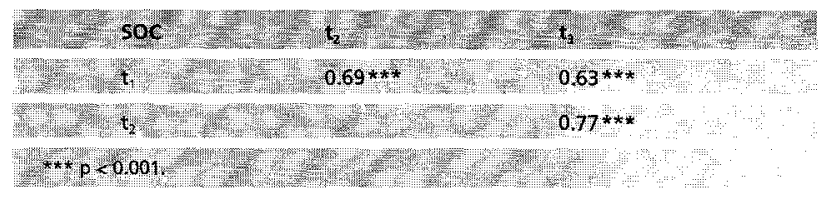

Table 2 Test-retest reliability of the SOC scale, $N=341$ ( $t_{1}=$ initial assessment, $t_{2}=+12$ months, $t_{3}=+18$ months) 


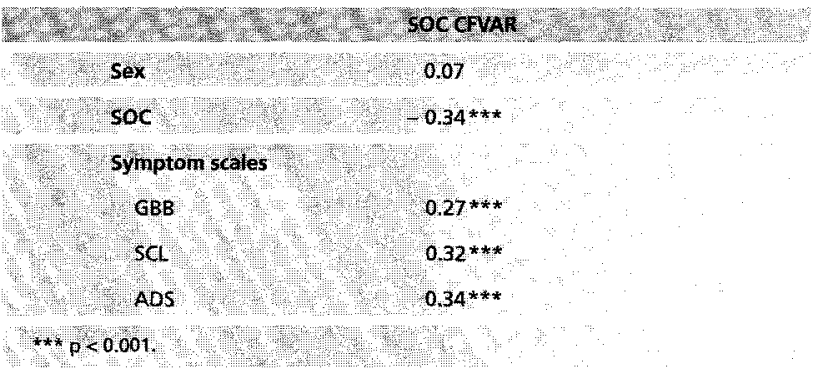

Table 3 Correlations between the SOC coefficient of variation (CFVAR) and sex, SOC and symptom scales at $t_{1}, \mathrm{~N}=341$

correlated with sex (Tab. 3). Higher symptom scores correlated with a greater variability of the SOC scale scores. The SOC CFVAR showed, independent of sex, significantly positive correlations with all three symptom scales GBB, $\mathrm{SCL}$, and ADS, and a significantly negative correlation with SOC scale scores at $t_{1}$. The latter result indicates that a higher SOC score at $t_{1}$ is associated with less variability of the SOC scale scores within the investigated period.

\section{Discussion}

We have presented data on sense of coherence in adolescents, which were collected in the context of a longitudinal study on health promotion programmes in two senior high schools. To date, only few studies have been published on the SOC in adolescence ${ }^{20,21}$. Therefore, it was of interest to investigate a larger sample of adolescents with regards to SOC levels as well as the course of the SOC scale score over time. Schuhmacher et al. ${ }^{9}$ reported a SOC mean score of 4.7 in a representative adolescent subgroup aged 16 to 19 years in a German epidemiological survey. The SOC mean scores of our sample are comparable with those from the German survey.

In addition to the lack of epidemiological data on the SOC in adolescents there is also a dearth of longitudinal studies. Only Antonovsky and Sagy's ${ }^{20}$ study used a two-point measurement design with an interval of only seven weeks to explore the influence of SOC on emotional responses to stress (i. e., evacuation from homes to other settlements). In our study we were able to assess students three times over a period of 18 months.

The first aim of the present study was to examine the mean SOC scale scores in female and male adolescents. Young men had a significantly higher SOC mean score at all three measurement points compared to young women. These results are in accordance with the reported mean scores from the German cross-sectional epidemiological survey ${ }^{9}$. As described by several authors ${ }^{28,29}$ males as compared with females tend to underreport mental problems and overestimate their own competence and coping resources. Thus, females' lower mean SOC scores are most probably a result of gender differences in self-reporting styles.

The SOC mean scores in adolescent males of our sample were comparable to those in the German survey. They almost reached the level of the SOC scores observed in adult men aged 20 to 40 in the epidemiological German sample. The SOC mean scores in female adolescents of our study also matched those of the epidemiological survey. However the mean SOC scores of both cohorts were lower than those of the adult women in the German sample 9 . In interpreting these findings, one should keep in mind that adolescent females underestimate their competence even more than adult women ${ }^{30,31}$.

Antonovsky ${ }^{1}$ claimed that a person emerges from childhood with a tentative sense of coherence that becomes more definitive in adolescence. He further suggested that individuals develop a generalised way of looking at the world as more or less coherent by around age 30 . We therefore raised the question whether SOC, like other adolescent characteristics, may be less stable in adolescence than in adulthood as a result of the nature of the adolescent period of development. Our data analyses of the three measurement points showed that SOC mean scores of male individuals reached almost the same level during the 12-month-observation period from $t_{1}$ to $t_{2}$, in females there was a slight, but not significant decrease. Between $t_{2}$ and $t_{3}$ the scores of the total sample increased significantly. When interpreting this result one has to take into account that the absolute differences of the mean scores were small and that the result was mainly determined by the female sample which outnumbers the male sample three times. The results suggest that SOC is already relatively stable in middle to late adolescence despite the developmental changes occurring during this age period. Moreover, when considering the psychometric properties of the SOC questionnaire found in this sample (i.e., the high test-retest reliability and internal consistency) one can endorse the use of this measure in adolescent samples, even at an age when personality is not yet fully developed.

As described in other studies using adult samples ${ }^{12,13}$ the SOC correlates with physical complaints and psychological disturbances. The data analyses from our study supported these findings. All symptom scales showed significantly negative correlations with the SOC scale. Obviously, a pathogenic concept (symptom scale scores being the operationalisation of the pathogenic concept) is expected to correlate negatively with a salutogenic concept (the SOC being an operationalisation of the salutogenic concept). However, as shown by other authors, the SOC scale is not merely a proxy 
measure of psychopathology but rather a partially independent, general measure of a person's world view: for instance, traumatic events such as life-threatening accidents may lead to a significant decrease of a person's SOC, even if psychiatric symptoms abate in the course of the rehabilitation period ${ }^{12}$.

Apparently, there is a certain individual variability in the SOC that correlates with physical and psychological symptoms and with the level of the SOC. On the one hand, a greater variability in sense of coherence can lead to uncertainty and thereby to more physical and psychological symptoms; on the other hand, an existing psychopathology may create greater variability in the $\mathrm{SOC}$ as a consequence.

Individuals with a high SOC score at the first measurement point showed less variability in the SOC scores over time than individuals with a low SOC score, independent of their sex. These findings support the hypothesis of Antonovsky and $\mathrm{Sagy}^{20}$ that SOC might be conceived of as a personality characteristic or coping style and adolescents may be characterised as having stronger or weaker sense of coherence. The greater variability of the SOC values in adolescents scoring low on the SOC scale may be explained by emotional ups and downs which change more rapidly and with a greater amplitude than in those adolescents with a stronger sense of coherence.

Several limitations of this study should be considered when interpreting the results. First, a relatively high number of subjects dropped out during the observation period. The dropouts differed significantly from the final study sample in that they reported more physical and psychological symptoms. This phenomenon was also seen in another longitudinal study of adolescents with disturbed eating behaviour ${ }^{32}$. Physically and psychologically impaired students often are academically less successful and leave high school before graduation ${ }^{22,32}$. Consequently they drop out of a longitudinal study. Second, the study sample is not representative of adolescents of that age in general as the participants are drawn only from two senior high schools and the student body is predominantly female. Third, the intervals between the three measurement points were not equal. However, as has been shown, the course of the SOC did not vary a great deal over time. Further longitudinal studies need to be conducted in samples investigating students from childhood through adulthood. This would provide more information about the development of SOC over a longer period of maturation and about further variables such as stressful life events and developmental risk factors which can influence the development and course of the SOC.

\section{Conclusion}

The course and development of the SOC scale scores over time in this sample of adolescents confirmed Antonovsky's theory that the sense of coherence develops throughout childhood and becomes more stable in adolescence. However, we found a certain variability in the SOC scale scores that correlated with physical and psychological symptoms, indicating that the sense of coherence may be less stable than originally claimed by Antonovsky. We draw the conclusion that the SOC questionnaire rather measures a psychological feature that lies somewhere between "state" and "trait".

\section{Acknowledgement}

The study was supported by grants from the Swiss National Science Foundation (NF-No. 32-046 787.96) and the EMDO Foundation (344/97)

Zusammentassung

\section{Kohärenzgefühl bei Jugendlichen}

Fragestellung: Mit der Studie solte die Entwicklung des Kohärenzgefuhis (Sense of Coherence) bel Jugendichen über einen Zeitraum von 13 Monaten untersucht werden. Ausserdem sollten Zusammenhänge zwischen individueller Variabilität des Kohärenzgefuhls und physischen und psychischen symptomen überprüft werden.

Methoden: Eine Stichprobe von 341 Gymnasiastinnen und Gymnasiasten wurde mit einem Fragebogen dreimal während eines 18 -monatigen Zeitraums untersucht. Der Fragebogen enthielt die Sense-of-Coherence-5cale (soc-13) und Messinstrumente zum grfassung von physischen und psychischen Beschwerden (GBE, SCL und ADS).

Ergebnisse: Mânnliche Jugendliche hatten im Vergleich $z u$ welblichen Jugendlichen signifikant höhere Mittelwerte auf der SOC-Skala. Es wutden signifikant negative Zusammenhänge zwischen der soc-skala und den symptomskalen bei beiden Geschlechtern gefunden. Höhere Werte aut den Symptomskalen korrellerten mit einer grösseren Variabilität in der soc-Skala. Unabhảngig vom Geschlecht zeigten Probanden mit einem hohen 50 C-skalenwert beim ersten Messzeitpunkt eine geringere Variabilitat in der Soc-Skala uber den Untersuchungszeitraum als Individuen mit einem niedrigen $50 \mathrm{C}$-Wert. Adoleszente, die niedrige Werte auf den Symptomskalen angaben, erreichten beinahe SOC-Werte, wie sie bei Erwachsenen gefunden werden: aussertem blieben die 50C-5kalen. werte bel tiesen Jugendlichen über den Untersuchungszeit* raum relativ stabíl. 
Schlussfolgerung: Die rrgebnisse weisen daraut hin, dass das Kohärenzgefüh gemessen mit der 50c-5kala in der mittleren bis späten Adoleszenz einen gewissen crad an stabilität aufweist:

Resume

\section{Sens de cohérence chez les adolescents}

Objectif: Certte étude a été portée sur le developement du sens de coherence (sense of coherence) chez les adolescents perdant dixwhit mois. La correbavion entre la variabilité individuelle dans le SOC at les symptômes à la tois physiques et psy chologinues y ont été examinés.

Méthode: Un échantillon de 341 étudiants provenant de deux colleges suisses a été étud̂́é au moven de trois questionnaires pendant dix-huit mois. Le questionalire comprenait une échelle de mesure du sens de coherence (Soc-13) ed dfférents moyens pour déteminer les problèmes physiques et psychologiques (GBB. ADS et SCL).

Résultats: Les adolescants masculins ont obtenu un score moyan SOC plus élevé de facon significative par rapport aux adolescentes féminines. Une correlation significativement négative a été trowvée antre le $50 \mathrm{C}$ a las échelles sympto. matiques dans les deux sexes. Des résultats élevés sur cetre échelle sont liés une plus grande vaviabilité dans le sens de cohérence. Independemment de leur sexe, les individus avec un score soc élevé au premier point de mesure ont montré une plus petite variabilité tans le $50 \mathrm{C}$ durant toute la durée du test comparés à leurs collegues avec un $50 \mathrm{C}$ bas. Chez les adolescents présentan un score bas le $50 \mathrm{C}$ a presque attein les niveaux vus chez les adultes et est resté relativement stable durantoute la durée.

Conclusion: Les résultats suggèrent un cerbin degré de stabilité du SOC dans Iradolescence moyenne a tardive.

\section{References}

1 Antonovsky $A$. Unraveling the mystery of health. How people manage stress and stay well. San Francisco: Jossey-Bass, 1987.

2 Antonovsky $A$. The structure and properties of the sense of coherence scale. Soc Sci Med 1993; 36: 725-33. German version: Rimann $M$, Udris J: Belastungen und Gesundheitsressourcen im Berufs- und Privatbereich (Stress and health resources in professional and personal life). Bericht 3. Personale und organisationale Ressourcen der Salutogenese. ETH Zürich: Institut für Arbeitspsychologie, 1993.

3 Bandura A. Self-efficacy: toward a unifying theory of behavioral change. Psychol Rev 1977; 84: 191-215.

4 Kobasa SC. Stressful life events, personality and health: an inquiry into hardiness. J Pers Soc Psychol 1979; 37: 1-11.

5 Werner $E$. High-risk children in young adulthood: a longitudinal study from birth to 32 years. Am J Orthopsychiat 1989; 59: 72-81.

6 Scheier MF, Carver CS. Optimism, coping, and health: assessment and implications of generalized outcome expectancies. Health Psychol 1985; 3: 219-47.
7 Cederblad M, Dahlin L, Hagnell O, Hansson $K$. Coping with life span crises in a group at risk for mental and behavioral disorders: from the Lundby study. Acta Psychiatr Scand 1995; 91: 322-30.

8 Langius A, Bjorwell $H$, Antonovsky A. The sense of coherence concept and its relation to personality traits in Swedish samples. Scand J Caring Sci 1992; 6: 165-71.

9 Schuhmacher J, Gunzelmann T, Brähler E. Deutsche Normierung der Sense of Coherence Scale von Antonovsky. Diagnostica 2000; 46: 208-13.

10 Carmel S, Bernstein J. Trait anxiety, sense of coherence and medical school stressors: observations at three stages. Anxiety Res 1990; 3: 51-60.

11 Geyer S. Some conceptual considerations on the sense of coherence. Soc Sci Med 1997; 44: 1771-9.

12 Schnyder U, Büchi S, Sensky T, Klaghofer R. Antonovsky's Sense of Coherence: trait or state? Psychother Psychosom 2000; 69: 296-302.

13 Sack $M$, Künsebeck $H$-W, Lamprecht $F$. Sense of Coherence and psychosomatic outcome: an empirical investigation on salutogenesis. Psychother Psychosom Med Psychol 1997; 47: 149-55.
14 Schnyder U, Büchi S, Mörgeli HP, Sensky T, Klaghofer R. Sense of Coherence - a mediator between disability and handicap? Psychother Psychosom 1999; 68: 102-10.

15 Anderzen I, Arnetz BB. Psychophysiological reactions to internal adjustment: results from a controlled, longitudinal study. Psychother Psychosom 1999; 68: $67-75$.

16 Flannery RB, Flannery GJ. Sense of coherence, life stress, and psychological distress: a prospective methodological inquiry. J Clin Psychol 1990; 46: 415-20.

17 Petrie K, Brook R. Sense of coherence, self-esteem, depression and hopelessness as correlates of reattempting suicide. $\mathrm{Br} \mathrm{J}$ Clin Psychol 1992; 31: 293-300.

18 Dahlin L, Cederblad M, Antonovsky A, Hagnell $O$. Childhood vulnerability and adult invincibility. Acta Psychiatr Scand 1990; 82: 228-32.

19 Sack $M$, Lamprecht $F$ Kohärenzgefühl und Salutogenese: Aaron Antonovskys Konzept gesundheitsprotektiver Ressourcen. In: Schüffel W, Brucks U, Johnen R, Köllner V, Lamprecht F, Schnyder U, eds. Handbuch der Salutogenese: Konzepte und Praxis. Wiesbaden: Ullstein Medical, 1998: 325-56. 
20 Antonovsky A, Sagy S. The development of a sense of coherence and its impact on responses to stress situations. J Soc Psychol 1986; 126: 213-25.

21 Margalit M, Eysenck S. Prediction of coherence in adolescence: gender differences in social skills, personality, and family climate. J Res Pers 1990; 24; 510-21.

22 Buddeberg-Fischer B, Klaghofer $R$, Reed $V$, Buddeberg $C$. Unterrichtsmodule zur Gesundheitsförderung. Ergebnisse einer kontrollierten Interventionsstudie. Soz Praventivmed 2000; 45: 191-202.

23 British Office of Population Censuses and Surveys. Standard Occupational Classification. Vol 3. London: HMSO, 1990

24 Frenz $A W$. Measuring Antonovsky's sense of coherence construct: a psychometric study. Diss Abstr Int 1990; 51 : 6141 .

25 Brähler E, Scheer JW. Der Giessener Beschwerdebogen GBB: Manual. 2 Aufl. Bern; Stuttgart; Wien: Huber, 1995.
26 Derogatis LR. SCL-90-R: Administration, scoring and procedure: manual II for the revised version. Clinical Psychometric Research, M.D., 1983. German version: Franke G. SCL-90-R: die Symptom-Checkliste von Derogatis. Deutsche Version. Manual. Göttingen: Beltz, 1995.

27 Hautzinger $M$, Bailer $M$. ADS. Allgemeine Depressionsskala: Manual. Weinheim: Beltz, 1993.

28 Reinherz HZ, Giaconia RM, Lefkowitz ES, Pakiz B, Frost AK. Prevalence od psychiatric disorders in a community population of older adolescents. J Am Acad Child Adolesc Psychiatry 1993; 32: 369-77.

29 Casper RC, Belanoff J, Offer D. Gender differences, but no racial group differences, in self-reported psychiatric symptoms in adolescents. J Am Acad Child Adolesc Psychiatry 1996; 35: 500-8.

30 Parsons JE, Meece JL, Adler TF, Kazcala $C M$. Sex differences in attributional patterns and learned helplessness. Sex Roles 1982; 8: 421-32.
31 Biddle $B J$. Recent development in role theory. Annual Rev Sociol 1986; 12: 67-92.

32 Buddeberg-Fischer B, Klaghofer R, Reed V, $B$ uddeberg $C$. Prevention of disturbed eating behaviour: a prospective intervention study in 14- to 19-year-old Swiss students. Acta Psychiatr Scand 1998; 98: 146-55.

\section{Address for correspondence}

PD Dr. med. Barbara Buddeberg-Fischer Department of Psychosocial Medicine University Hospital

\section{Culmannstrasse 8}

CH-8091 Zurich

Phone: ++41-1-255 5123

Fax: ++ 41-1-255 4384

e-mail: barbara.buddeberg@psy.usz.ch 